\title{
Cerebral microsomes. IV. On the attachment of ribosomes to the micro- somal membranes of rat cerebral cortex
}

The isolation and characterization of cerebral ribosomes and the delineation of their functional capacity have been the object of several recent studies (for review, see Datta ${ }^{5}$ ). Similarly, the aggregation of ribosomal monomers into polysomal clusters ${ }^{4,8,16}$, the size distribution of the latter ${ }^{2}$, the sensitivity of purified preparations of ribosomes and polysomes toward ions and the in vitro capacity of either population to incorporate radioactive precursors have been examined ${ }^{2,4,8,12,15}$. Intracellularly, nervous tissue ribosomes and polysomes have been shown to exist both free ${ }^{6,14}$ and in association with the membranes of the endoplasmic reticulum (rough microsomal membranes) $1,7,8,10,11,14$ but, although an extensive study of the ribosome-membrane interaction in hepatic tissue has appeared ${ }^{9}$, the mode of attachment of cerebral ribosomes to microsomal membranes has hitherto not been investigated.

The present communication describes the effect of ethylenediamine tetraacetic acid (EDTA) on membrane-bound ribosomes isolated from rat cerebral cortex. It is shown that, unlike hepatic membrane-bound ribosomes, the cerebral membranebound ribosomes are not released by the chelating agent in two stages, with the small subunit detaching first. Rather, a concerted and virtually synchronous detachment of both subunits seems to occur. Once detached, the two subunits exhibit differential sensitivity to EDTA, the smaller subunit being more labile.

The experiments were carried out with microsomes prepared as previously described 1,10 , except that the sucrose-free isolation medium was supplemented with $20 \mathrm{~m} M$ Tris (pH 7.2), $4 \mathrm{~m} M \mathrm{Mg}^{2+}$ and $25 \mathrm{~m} M \mathrm{~K}^{+}$(solution C) or $20 \mathrm{~m} M$ Tris (pH 7.2) and $10 \mathrm{mM} \mathrm{Mg}{ }^{2+}$ (solution $\left.\mathrm{E}\right)^{11}$. As shown elsewhere ${ }^{11}$, the microsomal pellet isolated in solution $\mathrm{C}$ consists of free ribo- and polysomes as well as of membrane-bound ribosomes and smooth membranes, whereas the pellet isolated in solution $\mathrm{E}$ lacks free RNA-containing particles and contains only membrane-bound RNA as well as smooth membranes. The latter pellet thus compares to the twice gradient-sedimented hepatic microsomal pellet used by Sabatini et al. ${ }^{9}$. Since microsomes isolated,

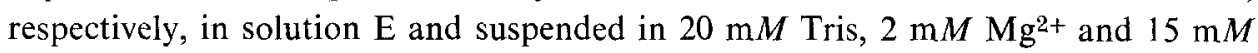
$\mathrm{Na}^{+}$and those isolated in solution $\mathrm{C}$ and subsequently 'purified' of free ribosomes by sedimentation through a 5-20\% gradient of sucrose in $20 \mathrm{mM}$ Tris and $2 \mathrm{mM} \mathrm{M \textrm {M } ^ { 2 + }}$ $(63,500 \times g, 2 \mathrm{~h})$, gave almost identical dissociation patterns, only the results obtained with the former are presented.

For control purposes, the EDTA-elicited dissociation of free cerebral riboscmes ${ }^{7,16}$ was also examined, as this served the purpose of calibrating the sedimentation values of the experimental subunit peaks. Ribosomes were prepared from microsomal pellets isolated in solution $\mathrm{C}$ according to Zomzely et al. ${ }^{15}$, except that the concentration of deoxycholate was raised to $0.37 \%$. The ribosomal pellet was

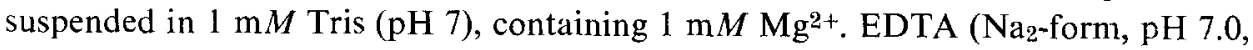
$0.4 \mathrm{M}$ ) was added to microsomal or ribosomal suspensions derived from $\mathrm{I} g$ of original cortex. The samples were kept on ice for $10 \mathrm{~min}$, layered on gradients and centrifuged for $8 \mathrm{~h}$ and $45 \mathrm{~min}$ at $63,500 \times g$ (Spinco $\mathrm{SW}-25.1$ rotor). The concentrations of 


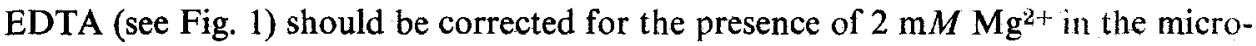
somal suspension medium.

Gradients were pumped through a hole in the bottom of the centrifuge tube and were continuously monitored at $254 \mathrm{~m} \mu$ (LKB Uvicord, model 8300 A provided with a rectangular flow-type cell, $4 \mathrm{~mm}$ path length, attached to an LKB recorder, model 6520 A). The effluent was drop-collected in an LKB UltroRac fraction collector.
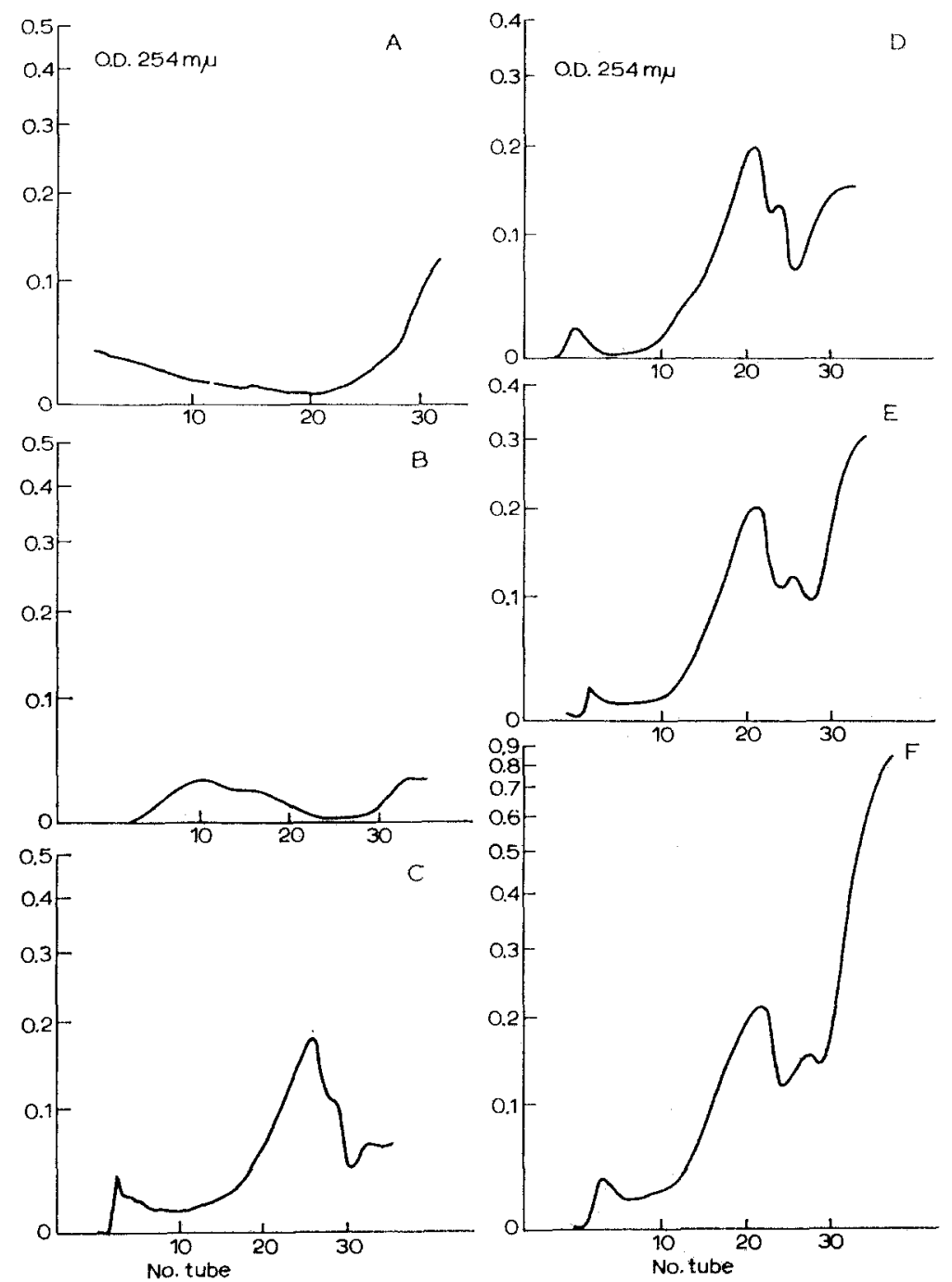

Fig. 1. Sedimentation profiles of microsomal preparations isolated from rat cerebral cortex in $20 \mathrm{~m} M$

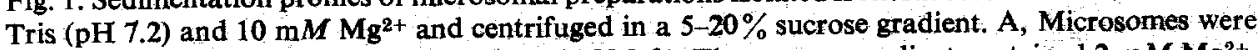
suspended in $20 \mathrm{mM}$ Tris (pH 7.2) and $10 \mathrm{mM} \mathrm{Mg}^{2+}$. The sucrose gradient contained $2 \mathrm{mM} \mathrm{Mg}^{2+}$, Centrifugation: 2 h at 63,500 $\times g$ (Spinco $S W-25.1$ rotor). B, Microsomes were suspended in $20 \mathrm{~m} M$ Tris (pH 7.2), $2 \mathrm{mM} \mathrm{Mg} \mathrm{Mg}^{2+}$ and $15 \mathrm{mM} \mathrm{Na}$ and were centrifuged for $8 \mathrm{~h}$ and $45 \mathrm{~min}$ at $63,500 \times g$ (Spinco rotor SW-25.1) in an ion-free gradient. C-F, EDTA was added to the suspension medium as follows: C, $10 \mathrm{mM} ; \mathrm{D}, 40 \mathrm{mM} ; \mathrm{E}, 100 \mathrm{~m} M$ and $\mathrm{F}, 200 \mathrm{mM}$. Centrifugation was as in $\mathrm{B}$. 
Figs. $1 \mathrm{~A}$ and $\mathrm{B}$ show the sedimentation profiles of microsomes sedimented, respectively, for $2 \mathrm{~h}$ in a gradient containing $2 \mathrm{mM} \mathrm{Mg^{2+ }}$ and for $8 \mathrm{~h}$ and $45 \mathrm{~min}$ in an ionfree gradient. The absence of free ribosomes and ribosomal aggregates in the former preparation is clearly indicated (Fig. 1A); the pattern of Fig. 1B reveals small amounts of rather heavy material in the gradient, probably the result of spontaneous release of particulate RNA during the prolonged centrifugation in an ion-free medium.

The progressive dissociation of membrane-bound ribosomes by EDTA is shown in Fig. 1C-F. The peaks were compared to subunit standards obtained by dissociating free ribosomes in the presence of $20 \mathrm{~m} M$ EDTA (see above). This yielded a subunit pattern, closely resembling the hepatic one ${ }^{9}$, i.e. an approximately 2 to 1 ratio of the large to the small subunit.

Upon addition of $10 \mathrm{~m} M$ EDTA to $1 \mathrm{~g}$ tissue equivalent of microsomes, a particulate material sedimenting as a large subunit together with material appearing as a shoulder in the descending, slow-sedimenting limb, was released. Increasing EDTA to $40 \mathrm{~m} M$ revealed a secondary peak in lieu of the shoulder, with sedimentation characteristics of the small subunit. Beginning at $40 \mathrm{mM}$ EDTA considerable destruction of particulate RNA occurred, preferentially at the expense of the small subunit (Figs. 1E and F). At $400 \mathrm{~m} M$ EDTA (not shown) only the large subunit peak remained; it was destroyed by $600 \mathrm{~m} M$ EDTA.

The sedimentation profiles obtained suggest a mechanism of ribosomal release in which detachment of the ribosome and its dissociation into subunits are virtually synchronous events. Whether this peculiar property of cerebral ribosomes relates to the known in vitro differences between cerebral and hepatic protein synthetic systems ${ }^{2,4,8,12}$ cannot be stated at this time. Another possibility should be entertained, namely that the apparent specificity of ribosome-membrane interactions, noted in other systems ${ }^{13}$ as well, is coded for, and conferred by the membrane $e^{3,9,10}$.

This research was supported by the United States Public Health Service grant NB 06294-01.

Mental Health Research Institute,

JULIO M. AZCURRA

University of Michigan Medical Center, OTTO Z. SELLINGER

Ann Arbor, Mich. 48103 (U.S.A.)

1 de Balbian Verster, F., Sellinger, O. Z., and Harkin, J. C., Morphological and biochemical correlates of cerebral microsomes. I. Isolation and chemical characterization, J. Cell Biol., 25 (1965) 69-80.

2 CAmpagnoni, A. T., AND MaHLER, H. R., Isolation and properties of polyribosomes from cerebral cortex, Biochemistry, 6 (1967) 956-967.

3 Chefurka, W., and Hayashi, Y., The effect of trypsin on rough endoplasmic membranes, Biochem. biophys. Res. Commun., 24 (1966) 633-638.

4 Clouet, D. H., Ratner, M., AND Williams, N., C ${ }^{14}$-leucine incorporation into brain ribosomes, Biochim. biophys. Acta, 123 (1966) 142-150.

5 DATTA, R. K., Brain ribosomes, Brain Research, 2 (1966) 301-322.

6 EKholm, R., ANd Hyden, H., Polysomes from microdissected fresh neurons, J. Ultrastr. Res., 13 (1965) 269-280. 
7 Jacob, M., Samec, J., Stevenin, J., Garel, J. P., And Mandel, P., Polysomes and polysomal RNA of rat brain, J. Neurochem., 14 (1967) 169-178.

8 Murthy, M. R. V., Protein synthesis in growing rat tissues. II. Polyribosome concentration of brain and liver as a function of age, Biochim. biophys. Acta, 119 (1966) $599-613$.

9 Sabatini, D. D., Tashiro, Y., and Palade, G. E., On the attachment of ribosomes to microsomal membranes, J. molec. Biol., 19 (1966) 503-524.

10 Sellinger, O. Z., de Balbian Verster, F., Sullivan, R. J., and Lamar, C., Jk., Morphological and biochemical correlates of cerebral microsomes. II. A study of the structural association of glutamine synthetase, ATP-ase and an esterase acting on o-nitrophenyl acetate, $j$. Neurochem., 13 (1966) 501-513.

11 Sellinger, O. Z., ANd Azcurra, J. M., Cerebral microsomes. III. The partition of glutamine synthetase between smooth and rough microsomal membranes. Symp. Metabolism of Nucleic Acids and Proteins and the Function of the Neuron, Liblice, Czechoslovakia, May, 1967, in press.

12 Stenzel, K. H., Aronson, R. F., And Rubin, A. L., In vitro synthesis of brain protein. II. Properties of the complete system, Biochemistry, 5 (1966) 930-936.

13 Suss, R., Blobel, G., AND PItot, H. C., Rat liver and hepatoma polysome-membrane interaction in vitro, Biochem. biophys. Res. Commun., 23 (1966) 299-304.

14 ToschI, G., A biochemical study of brain microsomes, Exp. Cell Res., 16 (1959) 232-255.

15 Zomzely, C. E., Roberts, S., AND Rapaport, D., Regulation of cerebral metabolism of anino acids. III. Characteristics of amino acid incorporation into protein of microsomal and ribosomal preparations of rat cerebral cortex, $J$. Neurochem., 11 (1964) 567-582.

16 Zomzely, C. E., Roberts, S., Brown, D. M., And Provost, C., Cerebral protein synthesis. I. Physical properties of cerebral ribosomes and polyribosomes, J. molec. Biol., 20 (1966) 455-468.

(Accepted July 17th, 1967) 